\title{
PENGARUH PANJANG SERAT TERHADAP KEKUATAN IMPAK KOMPOSIT ENCENG GONDOK DENGAN MATRIKS POLIESTER
}

\author{
Pramuko I Purboputro \\ Jurusan Teknik Mesin Universitas Muhammadiyah Surakarta \\ Jl. A. Yani Tromol Pos 1 Pabelan Kartasura
}

\begin{abstract}
ABSTRAK
Pemanfaatan material komposit pada saat ini semakin berkembang, seiring dengan meningkatnya penggunaan bahan tersebut yang semakin meluas mulai dari yang sederhana seperti alat-alat rumah tangga sampai sektor industri. Penelitian komposit diperkuat serat enceng gondok ini bertujuan mengetahui kekuatan tarik, kekuatan impak, kekuatan bending komposit serat enceng gondok dengan panjang $25 \mathrm{~mm}, 50 \mathrm{~mm}$ dan $100 \mathrm{~mm}$ dengan fraksi volume 80\% matrik polyesterdan $20 \%$ serat enceng gondok. Dari hasil pengujian didapat harga kekuatan tarik tertinggi dimiliki oleh komposit dengan panjang serat 100 mm yaitu 11,02 MPa, dengan modulus elastisitas 11023,33 MPa, Harga impak tertinggi dimiliki oleh komposit dengan panjang serat $50 \mathrm{~mm}$ yaitu 0,002344 $\mathrm{j} / \mathrm{mm}^{2}$.
\end{abstract}

Kata Kunci :Serat Enceng Gondok,Panjang Serat,Kekuatan Impak.

\section{PENADAHULUAN}

Penggunaan dan pemanfaatan material komposit dewasa ini semakin berkembang, seiring dengan meningkatnya penggunaan bahan tersebut yang semakin meluas mulai dari yang sederhana seperti alat-alat rumah tangga sampai sektor industri baik industri skala kecil maupun industri skala besar. Komposit mempunyai keunggulan tersendiri dibandingkan dengan bahan teknik alternative lain seperti kuat, ringan, tahan korosi, ekonomis dsb.

Serat enceng gondok merupakan salah satu material natural fibre alternatif dalam pembuatan komposit secara ilmiah pemanfaatannya masih dikembangkan, karena belum ditemukan material komposit yang menggunakan serat enceng gondok. Serat enceng gondok sekarang banyak digunakan dalam industri-industri mebel dan kerajinan rumah tangga karena selain mudah didapat, murah, dapat mengurangi polusi lingkungan (biodegradability) sehingga komposit ini mampu mengatasi permasalahan lingkungan, serta tidak membahayakan kesehatan. Pengembangan serat enceng gondok sebagai material komposit ini sangat dimaklumi mengingat dari segi ketersediaan bahan baku serat alam, Indonesia memiliki bahan baku yang cukup melimpah.

Dari pertimbangan-pertimbangan diatas maka penelitian ini dilakukan untuk mendapatkan data kemampuan mekanis dan fisis berupa kekuatan tarik, kekuatan bending, dan kekuatan impack dari komposit serat enceng gondok dengan matrik resin polyester.

Agar permasalahan yang dibahas tidak melebar maka perlu diadakan pembatasan masalah sebagai berikut :

1. Bentuk spesimen

Bentuk spesimen komposit adalah plat dengan fraksi volume serat enceng 
gondok 20\% ( tetap ) dengan panjang serat $25 \mathrm{~mm}, 50 \mathrm{~mm}$, dan $100 \mathrm{~m}$. Karena cara memperoleh serat enceng gondok menggunakan cara manual (tanpa permesinan ) tidak semua serat memiliki kualitas dan panjang yang sama.

2. Bahan benda uji

Benda uji dibuat menggunakan serat enceng gondok dengan kadar air 20\% menggunakan matrik resin polyester.

3. Cara pembuatan benda uji

4. Benda uji dibuat dengan cara hand lay up dan dengan penekanan secara manual menggunakan kaca sebagai cetakan dan penekan.Pengujian komposit

Pengujian komposit berupa uji kekuatan impack, struktur

\section{TINJAUAN PUSTAKA}

Pemikiran tentang penggabungan atau kombinasi bahan-bahan kimia atau elemen-elemen struktur dapat dilakukan dengan berbagai tujuan,tetapi dalam bidang engenering tujuan dari konsep penggabungan ini harus dibatasi, yaitu hasil dari penggabungan itu harus dapat diaplikasikan untuk mengatasi masalah yang ada saat ini,atau paling tidak dengan kebutuhan perencanaan suatu komponen struktur (Hadi,1997).

Bahan komposit sebenarnya banyak sekali terdapat di alam karena bahan komposit terdiri dari bahan organik maupun bahan anorganik, misalnya bamboo, kayu, serat enceng gondok, tebu, dan sebagainya. Secara tidak sadar sebenarnya kita telah mengenal berbagai jenis komposit. Seorang petani memperkuat tanah liat dengan jerami, pengrajin besi membuat pedang secara berlapis, dan beton bertulang merupakan beberapa jenis komposit yang sudah lama kita kenal (Diharjo,2003).

\section{Pengertian Komposit}

Sebetulnya kita mengetahui bahwa material/bahan terdiri dari logam, polimer, keramik dan komposit. Masing-masing material mempunyai keunggulan masingmasing.

Komposit serat adalah komposit yang terdiri dari fiber didalam matriks. Secara alami serat yang panjang mempunyai kekuatan yang lebih dibanding serat yang berbentuk curah (bulk). Serat panjang mempunyai struktur yang lebih sempurna karena struktur kristal tersusun sepanjang sumbu serat dan cacat internal pada serat lebih sedikit dari pada material dalam bentuk curah. Bahan pangikat atau penyatu serat dalam material komposit disebut matriks. Matriks secara ideal seharusnya berfungsi sebagai penyelubung serat dari kerusakan antar serat berupa abrasi, pelindung terhadap lingkungan (serangan zat kimia, kelembaban), pendukung dan menginfiltrasi serat, transfer beban antar serat, dan perekat serta tetap stabil secara fisika dan kimia setelah proses manufaktur. Matriks dapat berbentuk polimer, logam, karbon, maupun keramik. 
Tabel 1. Sifat mekanik dari beberapa jenis material

\begin{tabular}{|c|c|c|c|c|c|c|c|c|c|c|c|}
\hline \multirow[t]{2}{*}{ Type (acronym) } & \multicolumn{2}{|c|}{$\begin{array}{l}\text { Tensile Yield } \\
\text { Strength }\end{array}$} & \multirow{2}{*}{$\begin{array}{c}\text { Elon } \\
\text { gatio } \\
n \\
(\%)\end{array}$} & \multicolumn{2}{|c|}{$\begin{array}{l}\text { Flexural } \\
\text { Strength }\end{array}$} & \multicolumn{2}{|c|}{$\begin{array}{c}\text { Tensile } \\
\text { Modulus Of } \\
\text { Elasticity }\end{array}$} & \multicolumn{2}{|c|}{$\begin{array}{l}\text { Impact } \\
\text { Strength }\end{array}$} & \multicolumn{2}{|c|}{ Density } \\
\hline & Ksi & ( Mpa ) & & Ksi & (Mpa) & Ksi & ( Gpa ) & $\mathrm{Ft} \mathrm{lb/in}$ & $(\mathrm{J} / \mathrm{m})$ & 1b/in3 & ( sp.gr.) \\
\hline $\begin{array}{l}\text { Polytetrafluoroethyle } \\
\text { ne (PTFE) }\end{array}$ & 4.5 & 31 & 300 & - & - & 51 & 0,35 & 3 & 88 & 0.08 & 2.2 \\
\hline $\begin{array}{c}\text { Polybutylene } \\
\text { terephthlate (PBT) }\end{array}$ & 8 & 55 & 150 & 12 & 83 & - & - & 0,8 & 23,6 & 0.05 & 1.31 \\
\hline Polysulfone (PSU) & 16,2 & 70 & 75 & $\begin{array}{c}15 \\
4\end{array}$ & 106 & 360 & 2,48 & 1,3 & 38,3 & 0,04 & 1,24 \\
\hline $\begin{array}{l}\text { Polymethilmethacryl } \\
\text { ate (PMMA) }\end{array}$ & 10,5 & 72 & 5 & 16 & 110 & 425 & 2,93 & 0,3 & 8,8 & $\begin{array}{c}0,04 \\
3\end{array}$ & 1,19 \\
\hline $\begin{array}{l}\text { Polyamide-imide } \\
\text { (PAI) }\end{array}$ & 26 & 179 & 15 & 30 & 207 & 750 & 5,17 & 2,5 & 73,7 & 0,05 & 1,4 \\
\hline Phenolic (PF) & 10 & 69 & $<1$ & 11 & 76 & $\begin{array}{c}105 \\
0\end{array}$ & 7.3 & 0.35 & 10.3 & 0.05 & 1.4 \\
\hline Polyimide (PI) & 13 & 90 & 4 & 18 & 124 & 630 & 4.3 & 0.75 & 22 & 0.05 & 1.43 \\
\hline Epoxy (EP) & 10,5 & 72 & 4 & 16 & 110 & 450 & 3,1 & 0,3 & 8,8 & 0,04 & 1,15 \\
\hline Polystyrene (PS) & 7.5 & 51,7 & 1,5 & $\begin{array}{c}12, \\
5\end{array}$ & 86 & 480 & 3.3 & 0,3 & 8.8 & 0,04 & 1,05 \\
\hline Polyethylene (PE) & 1.9 & 13 & 600 & - & - & 24 & 0.16 & - & - & $\begin{array}{c}0,03 \\
4\end{array}$ & 0,9 \\
\hline $\begin{array}{c}\text { Polyvinylchloride } \\
\text { (PVC) }\end{array}$ & 6.5 & 44,8 & 6 & 13 & 89 & 375 & 2.6 & 4 & 118 & $\begin{array}{c}0.05 \\
4\end{array}$ & 1,44 \\
\hline Polyester (UP) & 9,4 & 40 & 1,6 & 5,5 & 60 & 300 & 17,5 & 0.4 & 10.6 & $\begin{array}{c}0.03 \\
4\end{array}$ & 1.1 \\
\hline $\begin{array}{c}\text { Acrylomitrile } \\
\text { butadiene stryrene } \\
\text { (ABS) }\end{array}$ & 8 & 55 & 12 & 11 & 76 & 335 & 2.3 & 3 & 88 & 0.04 & 1,05 \\
\hline
\end{tabular}

\begin{tabular}{|c|c|}
\hline Jenis/Sifat & Berat Jenis \\
\hline Serat enceng gondok & $0,25 \mathrm{gr} / \mathrm{cm}^{3}$ \\
\hline Serat tebu & $0,36 \mathrm{gr} / \mathrm{cm}^{3}$ \\
\hline Serat pohon kelapa & $1,36 \mathrm{gr} / \mathrm{cm}^{3}$ \\
\hline
\end{tabular}

Sumber : kenneth G.Budinsky 
Pengujian di laboratorium Teknik Kimia

Universitas Muhammadiyah Surakarta.

$\sigma_{1}=E_{1} \cdot \varepsilon_{1}$

$\sigma_{1}=\sigma_{f} \cdot V_{f}+\sigma_{m} . V_{m}$

dimana

$\sigma_{1}=$ Tegangan tarik komposit (GPa)

$\varepsilon_{1}=$ Regangan pada arah longitudinal

Kekuatan impak benda uji dapat dihitung dengan persamaan berikut :
$E$ serap $=G \times R(\operatorname{Cos} \beta-\operatorname{Cos} \alpha)$ .3

dimana :

$\mathrm{G}=$ Berat beban/pembentur $(\mathrm{N})$

$\mathrm{R}=$ Jari-jari pusat putar ke titik berat pembentur (m)

$\mathrm{E}_{\text {serap }}=$ Energi yang terserap (N. mm)

$\alpha=$ Sudut ayunan tanpa benda uji

$\beta=$ Sudut ayunan mematahkan benda uji

\section{METODOLOGI PENELITIAN}

Diagram alur penelitian dapat dilihat pada gambar 1

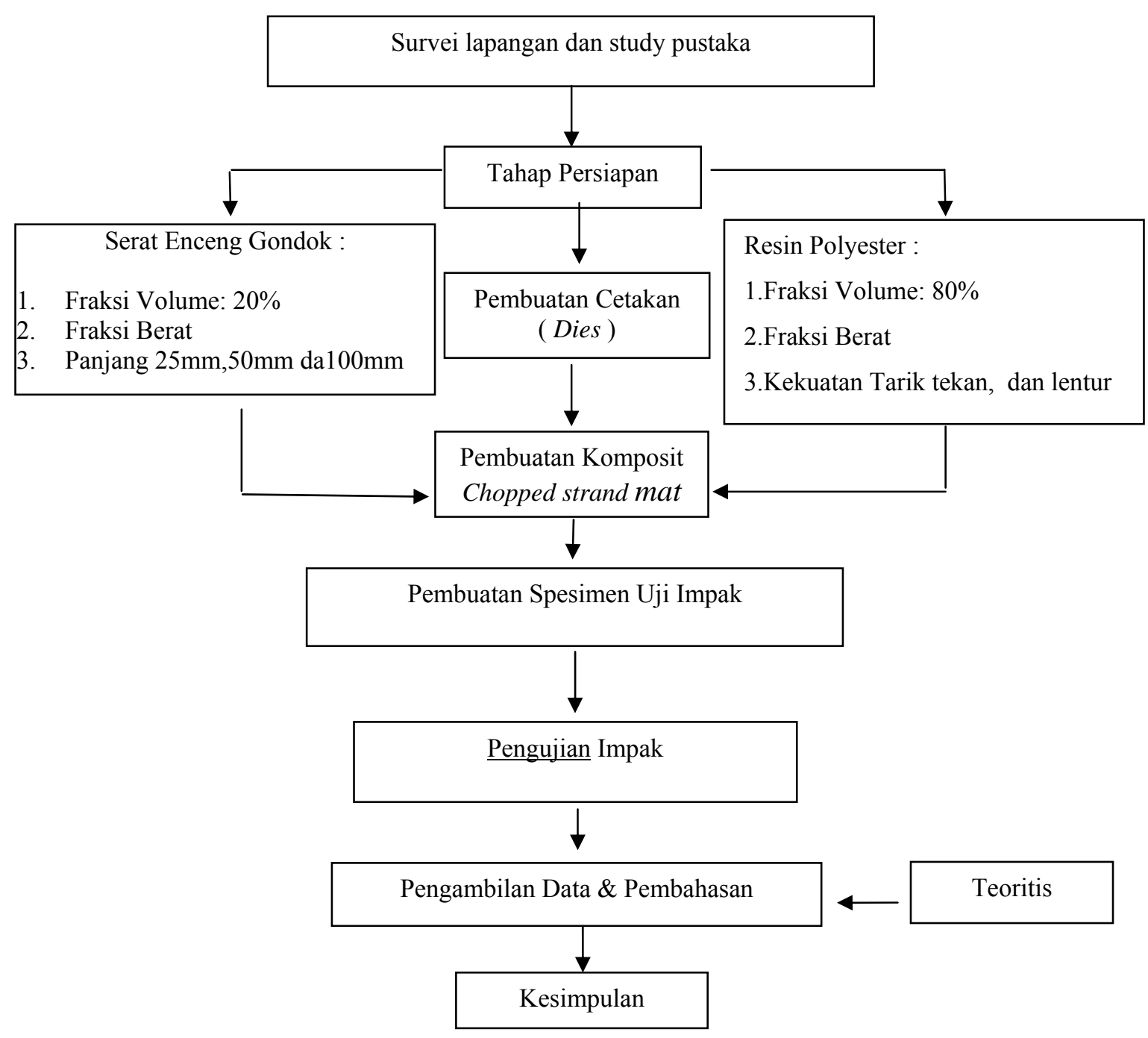

Gambar 1. Flowchart pengujian 


\section{Pembuatan Benda Uji}

Proses pembuatan komposit serat Enceng gondok dengan matrik polyester adalah sebagai berikut :

1) Tanaman enceng gondok dicuci,lalu dikeringkan selama \pm 10 hari..

2) Pembuatan cetakan

Untuk pengujiaan tarik menggunakan kaca dengan ketebalan $4 \mathrm{~mm}$ dengan ukuran 225 x $130 \mathrm{~mm}$ dan mempunyai daerah pencetakan 165 x $70 \mathrm{~mm}$, untuk pengujian impak menggunakan kaca dengan ketebalan $10 \mathrm{~mm}$ dengan ukuran 130 x $100 \mathrm{~mm}$ dan mempunyai daerah pencetakan 70 x $40 \mathrm{~mm}$, sedangkan untuk pengujian bending menggunakan kaca dengan ketebalan 4 mm dengan ukuran $210 \times 110 \mathrm{~mm}$ dan mempunyai daerah pencetakan $10 \times 50$ mm.

3) Pengambilan serat dari tanaman enceng gondok dengan menggunakan bantuan sikat kawat, tanaman enceng gondok tersebut setelah kering disikat dengan cara membujur searah dengan sikat kawat tersebut, lalu serat tersebut akan memisah dari daging tanaman tersebut. Srat tersebut lalu dipotong $25 \mathrm{~mm}, 50 \mathrm{~mm}, 100 \mathrm{~mm}$.

4) Pengolesan wax mold release atau kit mobil pada cetakan untuk memudahkan pengambilan benda uji dari cetakan.

5) Serat ditaruh dalam cetakan secara acak, lalu resin polyester dituangkan ke dalam cetakan tersebut.

6) Penutupan dengan menggunakan kaca yang bertujuan agar void yang kelihatan dapat diminimalkan jumlahnya yang kemudian dilakukan pengepresan dengan menggunakan plat besi yang dikencangkan dengan baut dan mur.

7) Proses pengeringan dibawah sinar matahari, proses ini dilakukan sampai benar-benar kering yaitu $5-10$ jam dan apabila masih belum benar-benar kering maka proses pengeringan dapat dilakukan lebih lama.

8) Proses pengambilan komposit dari cetakan yaitu menggunakan pisau ataupun cutter.

9) Benda uji komposit siap untuk dipotong menjadi spesimen benda uji.

10) Pengujian Impact

\section{HASIL DAN PEMBAHASAN \\ Pembahasan pengujian impact}

Untuk hasil pengujian impact, perbedaan harga impact rata-rata dari masing-masing jenis komposit tidak begitu besar. Hal itu disebabkan karena matrik yang digunakan hanya satu jenis yaitu polyester. Harga impact rata-rata yang tertinggi adalah komposit serat enceng gondok dengan panjang $25 \mathrm{~mm}$ yaitu $0,002344 \mathrm{~J} / \mathrm{mm}^{2}$ sedangkan yang terendah adalah komposit serat enceng gondok dengan panjang $100 \mathrm{~mm}$ yang mempunyai harga impact rata-rata $0,0010836 \mathrm{~J} / \mathrm{mm}^{2}$.

Perbedaan harga impact rata-rata dari ketiga jenis komposit dapat disebabkan oleh beberapa sebab diantaranya adalah kekuatan komposit yang kurang merata disetiap tempat dan distribusi serat yang kurang merata sehingga energi yang diserap menjadi lebih kecil. Sedangkan

patahan yang terjadi adalah jenis patahan getas.

Hasil dari pengujian dapat dilihat pada tabel 2 dan gambar 3 dibawah.

\section{Tabel 2 Data-data hasil pengujian impact komposit Enceng Gondok dengan fraksi volume Serat $20 \%$, dan Matrik Polyester $\mathbf{8 0 \%}$}




\begin{tabular}{|c|c|c|c|c|c|c|c|}
\hline Jenis komposit & No & $\alpha^{\circ}$ & $\beta^{\circ}$ & $\begin{array}{l}\text { Ao } \\
\left(\mathrm{mm}^{2}\right)\end{array}$ & $\begin{array}{c}\text { Energi } \\
\text { Yang } \\
\text { Diserap (J) }\end{array}$ & $\begin{array}{c}\text { harga } \\
\operatorname{Impak}\left(\mathrm{J} / \mathrm{mm}^{2}\right)\end{array}$ & $\begin{array}{l}\text { Harga Impak } \\
\text { Rata- } \\
\text { rata }\left(\mathrm{J} / \mathrm{mm}^{2}\right)\end{array}$ \\
\hline \multirow{3}{*}{$\begin{array}{l}\text { Serat Enceng } \\
\text { Gondok } 25 \mathrm{~mm}\end{array}$} & 1 & 158 & 156 & 76.7163 & 0.1137 & 0.001482 & \multirow{3}{*}{0.001615} \\
\hline & 2 & 158 & 155.5 & 75.065 & 0.14361 & 0.001913 & \\
\hline & 3 & 158 & 156 & 78.032 & 0.1137 & 0.00145 & \\
\hline \multirow{3}{*}{$\begin{array}{c}\text { Serat Enceng } \\
\text { Gondok } 50 \mathrm{~mm}\end{array}$} & 1 & 158 & 155 & 75.348 & 0.1740 & 0.00230 & \multirow{3}{*}{0.002344} \\
\hline & 2 & 158 & 154 & 73.440 & 0.2367 & 0.00322 & \\
\hline & 3 & 158 & 156 & 75.795 & 0.1137 & 0.001500 & \\
\hline \multirow{3}{*}{$\begin{array}{c}\text { Serat Enceng } \\
\text { Gondok } 100 \mathrm{~mm}\end{array}$} & 1 & 158 & 156 & 82.712 & 0.1182 & 0.00142 & \multirow{3}{*}{0.0010836} \\
\hline & 2 & 158 & 156.5 & 79.575 & 0.0844 & 0.001060 & \\
\hline & 3 & 158 & 157 & 72.122 & 0.0556 & 0.0007709 & \\
\hline
\end{tabular}

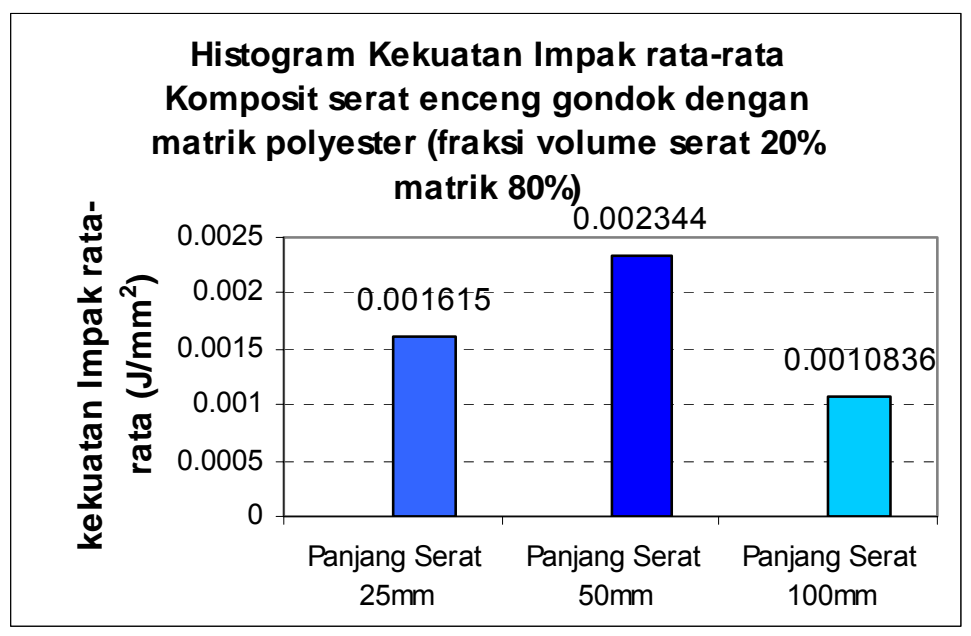

Gambar 2. Histogram kekuatan impak

\section{KESIMPULAN}

1. Semakin panjang serat maka harga impak akan semakin menurun, karena ikatan antara matriks dan serata semakin kuat sehinga serat akan patah pada garis patahnya

2. Kekuatan impak maksimum terjadi pada panjang serat $50 \mathrm{~mm}$, engan kekuatan harga impak ,002344

\section{DAFTAR PUSTAKA}

ASTM, 1990, Standards and Literature References for Composite Materials, 2d ed., American Society for Testing and Materials, Philadelphia, PA.

Budinski, Kenneth, 2000, Engineering Materials Properties and Selection sixth Edition,

Prentice Hall, New Jersey. 
Gibson.Ronald F., 1994, Principles Of Composite Material Mechanics, Mc Graw Hill Inc, New York.

Jamasri, 2002, Buku Pegangan Kuliah Komposit, Surakarta

Jones, M. R.,1975, Mechanics of Composite Materials, Mc Graw Hill Kogakusha, Ltd.

Roseno, Seto, 2003, Karakteristik dan Model Mekanis Material Komposit Berpenguat Serat Alam, , BPPT , Jakarta.

Shackelford James F, 1996, Introduction To Materials Science For Engineers, Prentice Hall International. Inc, London.

Staf Laboratorium Bahan Teknik, 2005., Petunjuk Praktikum Ilmu Logam,Teknik Mesin UGM, Yogyakarta.

Surdia T., Saito S, 1991, Pengetahuan Bahan Teknik, Pradnya Paramita, Jakarta.

Vlack Lawrence H.Van , 1995, Ilmu dan Teknologi Bahan, terjemahan Ir. Sriati Djaprie, Erlangga, Jakarta. 